\title{
A pragmatic study exploring the prevention of delirium among hospitalized older hip fracture patients: Applying evidence to routine clinical practice using clinical decision support
}

\author{
Jayna M Holroyd-Leduc ${ }^{*}$, Greg A Abelseth', Farah Khandwala', James L Silvius ${ }^{1}$, David B Hogan',
} Heidi N Schmaltz ${ }^{1}$, Cyril B Frank', Sharon E Straus ${ }^{2}$

\begin{abstract}
Delirium occurs in up to $65 \%$ of older hip fracture patients. Developing delirium in hospital has been associated with a variety of adverse outcomes. Trials have shown that multi-component preventive interventions can lower delirium rates. The objective of this study was to implement and evaluate the effectiveness of an evidence-based electronic care pathway, which incorporates multi-component delirium strategies, among older hip fracture patients. We conducted a pragmatic study using an interrupted time series design in order to evaluate the use and impact of the intervention. The target population was all consenting patients aged 65 years or older admitted with an acute hip fracture to the orthopedic units at two Calgary, Alberta hospitals. The primary outcome was delirium rates. Secondary outcomes included length of hospital stay, in-hospital falls, in-hospital mortality, new discharges to long-term care, and readmissions. A Durbin Watson test was conducted to test for serial correlation and, because no correlation was found, Chi-square statistics, Wilcoxon test and logistic regression analyses were conducted as appropriate. At study completion, focus groups were conducted at each hospital to explore issues around the use of the order set. During the 40-week study period, 134 patients were enrolled. The intervention had no effect on the overall delirium rate (33\% pre versus $31 \%$ post; $p=0.84)$. However, there was a significant interaction between study phase and hospital $(p=0.03)$. Although one hospital did not experience a decline in delirium rate, the delirium rate at the other hospital declined from $42 \%$ to $19 \%(p=0.08)$. This difference by hospital was mirrored in focus group feedback. The hospital that experienced a decline in delirium rates was more supportive of the intervention. Overall, post-intervention there were no significant differences in mean length of stay (12 days post versus 14 days pre; $p=0.74$ ), falls ( $6 \%$ post versus $10 \%$ pre; $p=0.43$ ) or discharges to long-term care ( $6 \%$ post versus $13 \%$ pre; $p=0.20$ ). Translation of evidence-based multi-component delirium prevention strategies into everyday clinical care, using the electronic medical record, was not found to be effective at decreasing delirium rates among hip facture patients.
\end{abstract}

\section{Background}

Delirium, or acute confusion, occurs in 25 to $65 \%$ of hospitalized patients treated for acute hip fracture $[1,2]$. Local data showed that orthopedic inpatients experienced the highest rates of delirium within the surgical subspecialties. Delirium is defined as an acute

\footnotetext{
* Correspondence: jayna.holroyd-leduc@albertahealthservices.ca 'Foothills Medical Center, $1403-29^{\text {th }}$ Street NW, Calgary, University of Calgary, Calgary, Alberta, Canada

Full list of author information is available at the end of the article
}

disturbance of consciousness accompanied by a change in cognition or by development of a perceptual disturbance [3]. Delirium develops over a short period of time, tends to fluctuate over time and is usually due to a general medical condition, substance intoxication, and/or substance withdrawal [3]. Hip fracture patients who develop delirium while in hospital have significantly worse outcomes than those who do not become delirious. Developing delirium in hospital has been associated with death, longer length of hospital stay, 
increased hospital-acquired complications, persistent cognitive deficits, and increased discharge rates to long-term care [4-7]. Delirium is also predictive of poor functional recovery among hip fracture patients $[5,8]$.

There are a number of preoperative factors that increase the risk of developing delirium after surgery, including age, cognitive and functional impairment, alcohol abuse, depression, abnormal preoperative electrolytes, depression, co-morbid disease, sensory impairment, and residing in a care facility $[9,10]$. Several hospital-related precipitating factors also exist, including physical restraints, malnutrition and dehydration, urinary catheters, three or more new medications, and any iatrogenic event [11]. The cause of delirium is rarely due to just one factor; instead, multiple precipitating factors typically contribute to its development [11].

Prevention is a key strategy when addressing delirium, as after it occurs it can have devastating consequences [4-8]. Interventions do not clearly affect the duration of delirium once it develops [12]. Given that multiple factors usually contribute to the development of delirium, randomized trials have shown multi-component preventative strategies to be most effective [12-15]. However, given resource restraints, these multi-component strategies are not always easy to translate and implement into routine clinical care [16].

The evidence base around appropriate dissemination and implementation strategies is imperfect [17]. Computerized clinical decision support systems, which are information systems designed to improve clinical decision-making at the point of care, are one form of knowledge translation found to be effective [18-20]. The objective of this study was to determine if incorporation of an evidence-based multi-component delirium prevention strategy into an electronic post-operative hip fracture clinical pathway, which is a form of clinical decision support, would result in a decrease in delirium rates and related outcomes among older hip fracture patients.

\section{Methods}

A pragmatic prospective cohort study using an interrupted time series design was conducted among patients admitted with a hip fracture to either of two Calgary, Alberta teaching hospitals [21]. All patients aged 65 years or older who were admitted for surgical repair of a hip fracture were eligible. Exclusion criteria included an inability to speak English, fractures caused by a motor vehicle crashes (given the mechanism of injury), or inability to consent to the study. Patients were monitored on the orthopedic wards for five months prior to implementation (October 2008 to March 2009) of the care pathway and then for five months post-implementation (March 2009 to August 2009).

The care pathway was developed with input from information technologists, decision makers, researchers and frontline healthcare providers from orthopedics, geriatrics, and nursing. The delirium prevention strategies within the care pathway were based on evidence obtained from multi-component delirium prevention trials conducted in acute care settings [12-15]. The care pathway was developed to require minimal instruction for use in order to maximize adherence and sustainability within the dynamic work environment of a hospital orthopedic ward. The developed care pathway was embedded into the existing post-operative hip fracture order set located on the hospitals' electronic medical record (Figure 1).

The care pathway also incorporates the Confusion Assessment Method (CAM) [22], which is a brief delirium diagnostic tool that is accurate (sensitivity $86 \%$, specificity 93\%), with high interobserver reliability [23]. Prior to the study, the CAM was introduced on the orthopedic wards in order to aide in recognition of delirium. It was incorporated into the electronic postoperative hip fracture order set.

The primary study outcome was change in delirium rates as determined using a validated chart-based method for identification of delirium [24]. Secondary outcomes included length of hospital stay, in-hospital mortality, documented falls in hospital, new discharges to longterm care, and hospital readmission rates within 30 days. Data collection techniques were standardized and kept consistent throughout the study using an operations manual. One of two trained chart abstractors reviewed the hospital chart of each enrolled hip fracture patient admitted during any one of 40 separate weekly assessment time periods ( 20 pre- and 20 post-implementation). Based on annual local hip fracture admission rates of approximately 400 across the two hospitals, five months post-intervention surveillance (40 data points overall) was felt to be sufficient to detect uptake into practice [25]. Outcome data were collected from the hospital chart of enrolled patients up until their discharge from hospital or to the end of the 10-month study period. Readmissions to hospital were tracked for one month post-discharge. Patients were eligible for enrollment only once. A Durbin Watson test was conducted to test for serial correlation between weekly delirium rates and, because no correlation was found, Chi-Square and Wilcoxon tests were used to make univariable comparisons, while logistic regression analyses was used to compare the effect of phase on delirium rates, while adjusting for hospital. No other change to practice was known to have occurred during the study. 


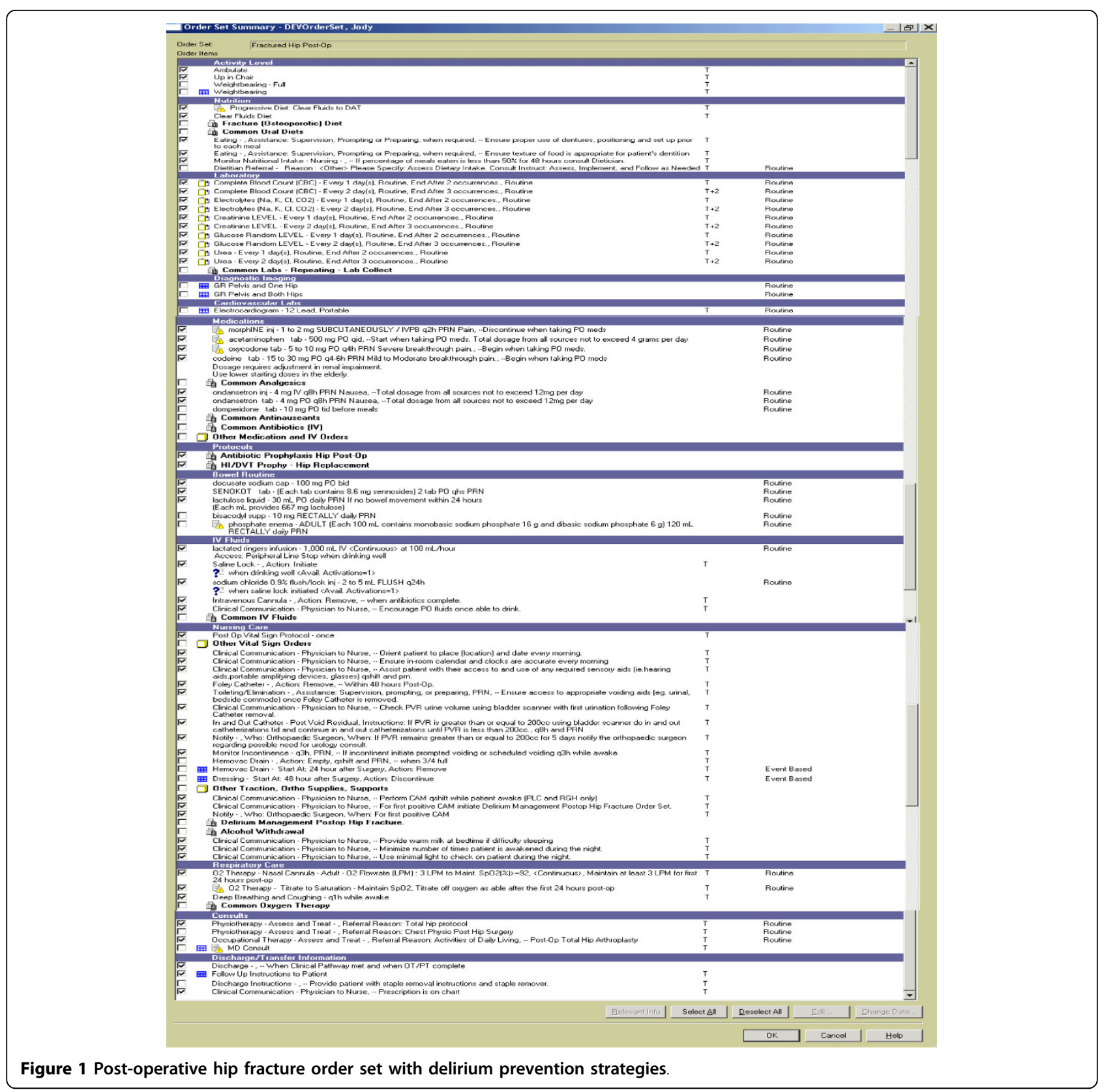

At study completion, focus groups (one at each hospital) were conducted with the frontline orthopedic nursing staff in order to explore issues around the implementation of the pathway. Nurses were recruited through postings and using snowball sampling. Participation was considered to be implied consent. Focus group participants were asked about facilitators and barriers to using the pathway, ease of use, and for specific feedback on its components. The focus groups were conducted, prior to analyzing the quantitative outcomes, by the principal investigator guided by a standardized list of questions. A research assistant took notes, which were later merged with data transcribed from audio recordings. The transcripts were coded by the investigator using a content analysis approach. Themes were identified and categorized. Only two focus groups were conducted due to limitations around the availability of frontline nurses to participate. This study received ethical approval from the University of Calgary Conjoint Health Research Ethics Board.

\section{Results}

During the 40-week study period, 343 patients were potentially eligible for enrolment (173 pre- and 170 
post-intervention). Among these patients 134 consented to participate, 21 declined participation, 138 were incapable of consenting, and 50 were determined to be otherwise ineligible. Among those enrolled, 102 were residing in their own home prior to their hip fracture.

The intervention had no effect on the overall delirium rate (Table 1). However, there was a significant interaction between study phase and hospital $(\mathrm{p}=0.033)$. Although one hospital (hospital two) did not experience a decline in their delirium rate, the delirium rate at the other hospital (hospital one) declined from $42 \%$ to $19 \%$ with the intervention ( $\mathrm{p}=0.076$; Figure 2$)$. There were no significant changes in hospital length of stay, falls, or discharges to long-term care facilities (Table 1). There was one death among those enrolled, and six patients were readmitted to hospital (two pre- and four postimplementation; $\mathrm{p}=0.340$ ).

When focus group participants were asked about barriers to using the pathway, both groups felt that there was too much information to read and that orders could be missed. Although both focus groups felt the delirium strategies were based on 'common sense,' one group felt the orders were insulting and the overwhelming consensus amongst this group was that the pathway was 'painful' to use. The other focus group felt the delirium strategies were useful reminders of good practice, and all these participants felt the pathway was easy to use. Participants in this second group also commented that the pathway (and doing the CAM) helped them to identify delirium and initiate management strategies earlier. This second group was from the hospital that experienced a $50 \%$ reduction in delirium rates.

\section{Discussion}

Our attempt to systematically incorporate evidencebased multi-component delirium prevention strategies
[12-15] into practice resulted in mixed success. Although we made efforts to obtain input from all levels of the healthcare team during development, this project highlights the importance of continuing to engage frontline personnel because of issues like staff turnover and the development of unexpected barriers [26]. The focus groups highlighted the potential impact of organizational culture, personnel changes, and structure on the uptake of the delirium prevention strategies. Multiple factors can influence the uptake of evidence by different stakeholder groups with challenges operating at different levels within the system [26].

Effective knowledge translation includes adaptation of the intervention to address identified barriers [27]. Specifically, the order set was subsequently redesigned to address the concerns of the focus groups about the volume of information included. Although the content has not markedly changed, formatting changes have reduced the total number of orders. The modified intervention is informing a provincial hip fracture care pathway currently under development.

\section{Limitations}

Although we used a validated chart-abstraction instrument, determining delirium rates was dependant on relevant information being recorded within the medical chart. Sample size calculations are challenging with interrupted time series studies [28]. We estimated that 40 data points would be sufficient to detect a change to practice [25]. However, we underestimated enrolment issues. Specifically, 138 patients were not enrolled due to issues around obtaining consent from patients. Extending the recruitment period was not feasible given funding limitations.

Table 1 Outcomes for the $\mathbf{1 3 4}$ hip fracture patients enrolled in the delirium prevention study

\begin{tabular}{|c|c|c|c|c|}
\hline Outcome & Pre-intervention & Post-intervention & Difference $(95 \% \mathrm{Cl})^{\mathrm{a}}$ & p value ${ }^{b}$ \\
\hline Delirium, n/N (\%) & $23 / 70(33)$ & $20 / 64(31)$ & $2(-14,17)$ & 0.840 \\
\hline Hospital 1, n/N (\%) & $14 / 33(42)$ & 4/21 (19) & $23(0,47)$ & 0.076 \\
\hline Hospital 2, n/N (\%) & 9/37 (24) & $16 / 43(37)$ & $-13(-33,7)$ & 0.220 \\
\hline Length of stay, median days (range) & $14(9-21)$ & $12(10-21)$ & $-0.03(-4.08,4.03)$ & 0.740 \\
\hline Hospital 1, median days (range) & $14(10-23)$ & $11(9-16)$ & $-1.7(-7.4,4.0)$ & 0.210 \\
\hline Hospital 2, median days (range) & $14(9-20)$ & $13(10-21)$ & $2.9(-2.9,8.7)$ & 0.630 \\
\hline Fall, n/N (\%) & $7 / 70(10)$ & 4/64 (6) & $4(-5,13)$ & 0.430 \\
\hline Hospital 1, n/N (\%) & 4/33 (12) & $1 / 21(5)$ & $7(-7,22)$ & 0.640 \\
\hline Hospital 2, n/N (\%) & $3 / 37(8)$ & $3 / 43(7)$ & $1(-11,13)$ & $>0.99$ \\
\hline New discharge to long-term care, n/N (\%) & 9/70 (13) & $4 / 64(6)$ & $7(-3,16)$ & 0.200 \\
\hline Hospital 1, n/N (\%) & 6/33 (18) & 1/21 (5) & $13(-3,29)$ & 0.230 \\
\hline Hospital 2, n/N (\%) & $3 / 37(8)$ & $3 / 43(7)$ & $1(-11,13)$ & $>0.99$ \\
\hline
\end{tabular}

${ }^{a}$ Estimated mean difference for continuous measures, estimated difference in proportions for categorical measures.

${ }^{b}$ Wilcoxon p-value for continuous measures, chi-square or Fisher's exact test p-value for categorical measures. 


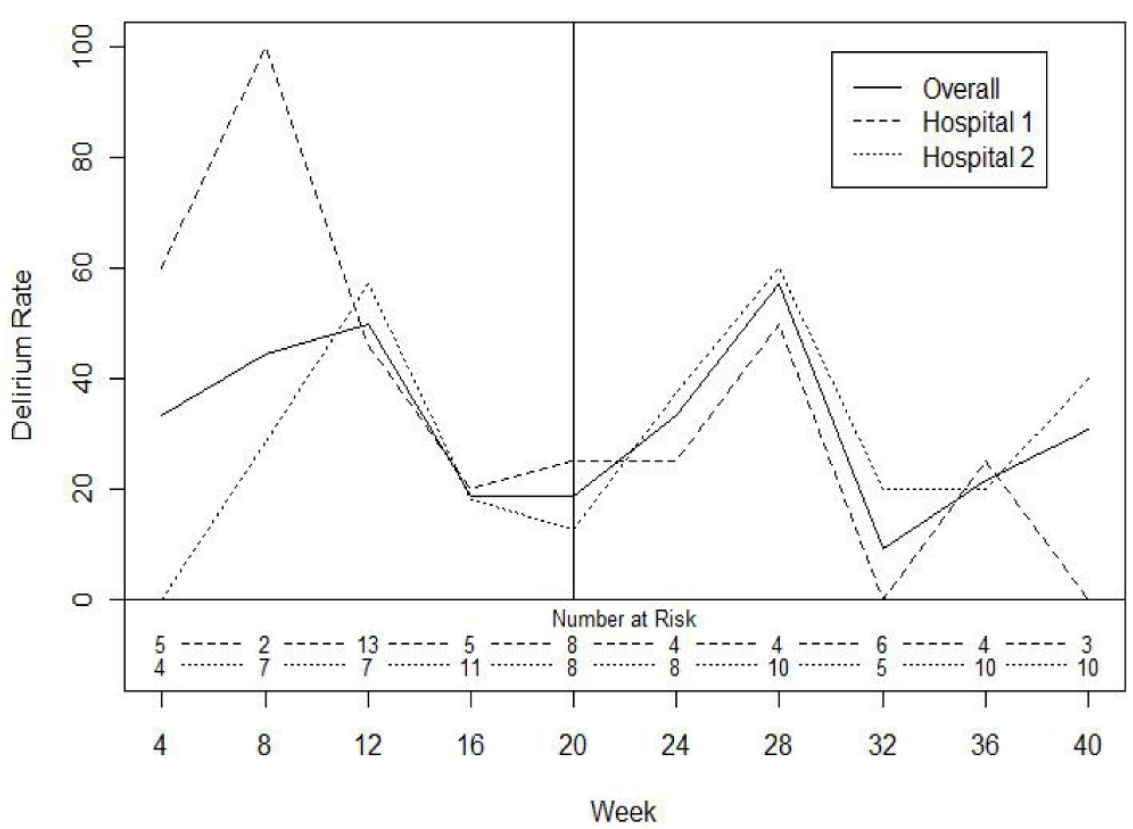

Figure 2 Change in delirium rates over time overall and by hospital.

\section{Conclusions}

Translation of evidence-based multi-component delirium prevention strategies into everyday clinical care, using an electronic health record, was not shown to be effective at decreasing delirium rates among hospitalized hip facture patients, although it was found to be clinically successful at one hospital. This project highlights the importance of end-user support when implementing evidence-based clinical decision support tools.

\section{Acknowledgements}

The authors thank Barbara Bobranska-Artiuch (University of Calgary), Fatima Chatur (University of Calgary), and Pierre Duez (University of Toronto) for their support in data collection and management. We also thank Kelly McDonald (Alberta Health Services) and Rishma Jessa (Alberta Health Services) for assisting with the CAM education and order set implementation, and Dr D. Burback (University of Calgary), Mollie Cole (Alberta Health Services), Jill Robert (Alberta Health Services), Steven Zack (Alberta Health Services) and Sarah Quigley (Alberta Health Services) for their input on the development of the order set and supporting its implementation. The participation of all the staff on the orthopedic wards was also much appreciated. This project was funded by a peer-reviewed KT grant from the former Calgary Health Region (now Alberta Health ServicesCalgary Zone). The funder had no role in the study other than to provide funding support.

\section{Author details}

${ }^{1}$ Foothills Medical Center, 1403-29 ${ }^{\text {th }}$ Street NW, Calgary, University of Calgary, Calgary, Alberta, Canada. ${ }^{2}$ University of Toronto, Toronto, Ontario, Canada.

\section{Authors' contributions}

All authors made substantial contributions to conception and design and to interpretation of data; FK analyzed the data; $\mathrm{JH}-\mathrm{L}$ contributed to the acquisition of data and drafted the manuscript; All authors were involved in revising the manuscript critically for important intellectual content and have given final approval of the version to be published.

\section{Competing interests}

The authors declare that they have no competing interests.

Received: 20 April 2010 Accepted: 22 October 2010

Published: 22 October 2010

\section{References}

1. Inouye SK: Delirium after hip fracture: to be or not to be? J Am Geriatr Soc 2001, 49(5):678-679.

2. Williams-Russo P, Urquhart BL, Sharrock NE, Charlson ME: Post-operative delirium: predictors and prognosis in elderly orthopedic patients. J Am Geriatr Soc 1992, 40(8):759-767.

3. DSM-IV-TR: Diagnostic and Statistical Manual of Mental Disorders The American Psychiatric Association, 42000.

4. Francis J, Kapoor WN: Prognosis after hospital discharge of older medical patients with delirium. J Am Geriatr Soc 1992, 40(6):601-606.

5. Gustafson Y, Berggren D, Brannstrom B, Bucht G, Norberg A, Hansson LI, et al: Acute confusional states in elderly patients treated for femoral neck fracture. J Am Geriatr Soc 1988, 36(6):525-530.

6. Inouye SK, Rushing JT, Foreman MD, Palmer RM, Pompei P: Does delirium contribute to poor hospital outcomes? A three-site epidemiologic study. J Gen Intern Med 1998, 13(4):234-242.

7. O'Keeffe $S$, Lavan J: The prognostic significance of delirium in older hospital patients. J Am Geriatr Soc 1997, 45(2):174-178.

8. Marcantonio ER, Flacker JM, Michaels M, Resnick NM: Delirium is independently associated with poor functional recovery after hip fracture. J Am Geriatr Soc 2000, 48(6):618-624.

9. Dasgupta $M$, Dumbrell AC: Preoperative risk assessment for delirium after noncardiac surgery: a systematic review. J Am Geriatr Soc 2006, 54(10):1578-1589.

10. Marcantonio ER, Goldman L, Mangione CM, Ludwig LE, Muraca B, Haslauer CM, et al: A clinical prediction rule for delirium after elective noncardiac surgery. JAMA 1994, 271(2):134-139.

11. Inouye SK, Charpentier PA: Precipitating factors for delirium in hospitalized elderly persons. Predictive model and interrelationship with baseline vulnerability. JAMA 1996, 275(11):852-857.

12. Inouye SK, Bogardus ST Jr, Charpentier PA, Leo-Summers L, Acampora D, Holford TR, et al: A multicomponent intervention to prevent delirium in hospitalized older patients. N Engl J Med 1999, 340(9):669-676. 
13. Marcantonio ER, Flacker JM, Wright RJ, Resnick NM: Reducing delirium after hip fracture: a randomized trial. J Am Geriatr Soc 2001, 49(5):516-522

14. Lundstrom M, Olofsson B, Stenvall M, Karlsson S, Nyberg L, Englund U, et al: Postoperative delirium in old patients with femoral neck fracture: a randomized intervention study. Aging Clin Exp Res 2007, 19(3):178-186.

15. Vidan M, Serra JA, Moreno C, Riquelme G, Ortiz J: Efficacy of a comprehensive geriatric intervention in older patients hospitalized for hip fracture: a randomized, controlled trial. J Am Geriatr Soc 2005, 53(9):1476-1482.

16. Reuben DB: Making hospitals better places for sick older persons. J Am Geriatr Soc 2000, 48(12):1728-1729.

17. Grimshaw JM, Thomas RE, MacLennan G, Fraser C, Ramsay CR, Vale L, et al: Effectiveness and efficiency of guideline dissemination and implementation strategies. Health Technol Assess 2004, 8(6):iii-iv, 1-72.

18. Garg AX, Adhikari NK, McDonald H, Rosas-Arellano MP, Devereaux PJ, Beyene J, et al: Effects of computerized clinical decision support systems on practitioner performance and patient outcomes: a systematic review. Jama 2005, 293(10):1223-1238.

19. Kawamoto K, Houlihan CA, Balas EA, Lobach DF: Improving clinical practice using clinical decision support systems: a systematic review of trials to identify features critical to success. Bmj 2005, 330(7494):765.

20. Shojania KG, Jennings A, Mayhew A, Ramsay CR, Eccles MP, Grimshaw J: The effects of on-screen, point of care computer reminders on processes and outcomes of care. Cochrane Database of Systematic Reviews 2009, 3, Art. No.: CD001096.

21. Gottman J: Time-series analysis New York: Cambridge University Press 1981.

22. Inouye SK, van Dyck CH, Alessi CA, Balkin S, Siegal AP, Horwitz Rl: Clarifying confusion: the confusion assessment method. A new method for detection of delirium. Ann Intern Med 1990, 113(12):941-948.

23. Wong CL, Holroyd-Leduc J, Simel DL, Straus SE: Does this patient have delirium? Value of bedside instruments. JAMA 2010, 304(7):779-786.

24. Inouye SK, Leo-Summers L, Zhang Y, Bogardus ST Jr, Leslie DL, Agostini JV: A chart-based method for identification of delirium: validation compared with interviewer ratings using the confusion assessment method. J Am Geriatr Soc 2005, 53(2):312-318.

25. Cook TD, Campbell DT: Quasi-experiments: interrupted time-series designs in quasi-experimentation: design and analysis issues for field settings Boston: Houghton Mifflin Company 1979.

26. Straus SE, Tetroe J, Graham I: Defining knowledge translation. CMAJ 2009, 181(3-4):165-168.

27. Graham ID, Logan J, Harrison MB, Straus SE, Tetroe J, Caswell W, et al: Lost in knowledge translation: time for a map? J Contin Educ Health Prof 2006, 26(1):13-24.

28. Ramsay CR, Matowe L, Grilli R, Grimshaw JM, Thomas RE: Interrupted time series designs in health technology assessment: lessons from two systematic reviews of behavior change strategies. Int I Technol Assess Health Care 2003, 19(4):613-623.

doi:10.1186/1748-5908-5-81

Cite this article as: Holroyd-Leduc et al: A pragmatic study exploring the prevention of delirium among hospitalized older hip fracture patients: Applying evidence to routine clinical practice using clinical decision support. Implementation Science 2010 5:81.

\section{Submit your next manuscript to BioMed Central and take full advantage of:}

- Convenient online submission

- Thorough peer review

- No space constraints or color figure charges

- Immediate publication on acceptance

- Inclusion in PubMed, CAS, Scopus and Google Scholar

- Research which is freely available for redistribution

Submit your manuscript at www.biomedcentral.com/submit 